\title{
Deep soft soil improvement by alkaline activation
}

Nuno Cristelo MEng, PhD

Associate Professor, Trás-os-Montes e Alto Douro University, Portugal

Stephanie Glendinning PhD

Reader in Environmental Geotechnics, Newcastle University, UK
Amândio Teixeira Pinto PhD

Associate Professor, Trás-os-Montes e Alto Douro University, Portugal

This research studied the use of alkaline activation of fly ash, as a silica and alumina amorphous source, to improve soft soils. A laboratory programme - including tests to study strength and deformability development, alternative curing methods, the effect of the different components of the grout, effect of raising initial temperature and comparison with a cement grout - was carried out. Laboratory tests revealed that the use of fly ash and alkaline activator resulted in a soil strength improvement up to $11.4,16.7$ and $43.4 \mathrm{MPa}$, at 28,90 and 365 days curing, respectively. The most effective combinations obtained in the laboratory were chosen for the field application with jet grouting. The grout performed adequately to pass standard engineering specifications for soil mixing, achieving up to $26.4 \mathrm{MPa}$ at 90 days curing. The main conclusion is the potential of alkaline activation for soil improvement, and therefore this research has created a basis for further studies.

\section{Introduction}

The alkali activation of materials containing silica + alumina has been researched and offers a potential alternative to cement in construction. Materials formed using reactions between silica and alumina and alkali cations such as sodium or potassium are very similar, at a molecular level, to natural rocks. Alkaline-activated materials have been shown to have improved mechanical characteristics at higher levels than cement. The amorphous chemical structure of fly ash makes its high levels of silica and alumina particularly applicable to alkaline activation, since its components are more susceptible to combination with sodium or potassium cations in this form. Therefore, alkali activation of fly ash offers a potential financial and environmental cost saving when used as a cement replacement. Jet grouting is an advanced technology, using cement slurry to improve the strength and stiffness of soft soils in situ and therefore offers a means of applying alkali activation as a ground improvement method. The aim of this study was to determine the potential of an alkaline-activated waste material to improve soft soils, particularly in depth, and the influence of several variables on strength gain. The research aims to understand if the activator/waste slurry is suitable to be used as a binder for the engineering improvement of a range of soils, and particularly as a substitute for Portland cement. It also included the evaluation of the effectiveness of the binder when used with jet grouting.

\section{Alkaline activation of fly ash}

The name 'geopolymerisation' refers to the dissolution of alumina $\left(\mathrm{Al}_{2} \mathrm{O}_{3}\right)$ and silica $\left(\mathrm{SiO}_{2}\right)$ from some materials in an alkaline environment and their subsequent polymerisation to form a new material. It was first used by Davidovits in 1976 (Pacheco-Torgal et al., 2007) when he generically designated 'geopolymers' as a term related to the products achieved by alkaline activation of kaolin. A geopolymer is basically a three-dimensional aluminosilicate mineral polymer formed by several amorphous to semicrystalline phases. These alkali-activated aluminosilicate binders are formed by reacting raw solids which are rich in silica and aluminium with a solution of alkali or alkali salts resulting in a mixture of gels and crystalline compounds that eventually harden into a new strong matrix (Feng et al., 2004). The polycondensation reaction occurs in a high alkaline environment that reorganises aluminium and silica in a more stable $\mathrm{Si}-\mathrm{O}-\mathrm{Al}$ type structure, resulting in materials with high mechanical strength and chemical stability (Wang et al., 2005).

The development of alkali-activated cements, which have a significant proportion of the alkali metals $\mathrm{Na}$ or $\mathrm{K}$ (between 3 and $20 \%$ ) in their composition, can be achieved by two main methods (Granizo, 1998).

(a) Compounds rich in calcium, such as lime, Portland cement, blastfurnace slag, etc., combined with alkaline earth metals, with composition

$$
\mathrm{Na}_{2} \mathrm{O}-\mathrm{CaO}-\mathrm{Al}_{2} \mathrm{O}_{3}-\mathrm{SiO}_{2}-\mathrm{H}_{2} \mathrm{O}
$$

(b) Soluble compounds of alkali metals combined with aluminosilicate materials (without the presence of any calcium), such as fly ash, metakaolin, burned clay and others, with composition

$$
\mathrm{Na}_{2} \mathrm{O}-\mathrm{Al}_{2} \mathrm{O}_{3}-\mathrm{SiO}_{2}-\mathrm{H}_{2} \mathrm{O}
$$

Both systems can be activated with sodium or potassium 
hydroxide, and the reactions will lead to fundamental modifications on the structure of the component materials. The research presented herein relates to the second group, since no calcium is involved. Palomo et al. (1999) summarise the main differences between both models in the following points.

(a) Composition of the material to be activated, essentially Si and $\mathrm{Ca}$ in the first case and $\mathrm{Si}$ and $\mathrm{Al}$ in the second.

(b) Concentration of the activator, being low to mild for the first model and high for the second.

As soon as the aluminosilicate material is mixed with the alkaline solution the hardening process begins, leaving insufficient time and space for the gel to transform into a well-crystallised structure, as is the case in zeolite formation (Hua and Deventer, 2000). These authors compared X-ray diffraction (XRD) patterns of different minerals before and after activation and concluded that after geopolymerisation all of the main characteristic peaks of $\mathrm{Al}-\mathrm{Si}$ decreased slightly in intensity, but still remained, suggesting that there was not a total dissolution into the gel phase. Furthermore, the fact that there were no new peaks suggested that no new major crystalline phases formed.

The great majority of aluminosilicates are crystalline in nature, making them highly stable in all but extreme environments. To promote the conditions for alkaline activation and to enhance the amount of polymerisation that takes place, the aluminosilicate raw materials should first be submitted to thermal treatment (Hua and Deventer, 2003). This will induce the loss of constituent water and the re-coordination of the aluminium and oxygen ions, which ultimately transforms the previously crystalline material into an amorphous one. These structural changes promote an environment in which chemical combinations more easily take place. For that reason, raw materials with a natural or artificial thermal history, such as fly ash, blastfurnace slag, Portland cement residues, pozzolanic wastes or metakaolin, are more suitable for alkaline activation than non-calcined materials such as clay or feldspars. For this reason, and also because of the environmental benefits of using a waste by-product ( $\mathrm{Hu}$ et al., 2009), fly ash was used in this investigation. Another possibility was metakaolin, but its cost is much greater than fly ash, which makes it much less advantageous for potential commercial applications of this technique. The laboratory investigation into the development of alkali-activated binders for soil stabilisation and a field trial using these binders are described herein.

\section{Laboratory research design}

The aim of the laboratory programme was to develop suitable alkali-activated binders for ground improvement using jet grouting. The specific objectives are listed here.

(a) Establish the most advantageous fly ash percentage for both strength and stiffness development rate. (b) Identify the effect of activator temperature on strength and stiffness.

(c) Understand how curing conditions affect the reactions.

(d) Determine the optimal activator concentration, as it constitutes the most expensive material involved in the process.

(e) Compare the effectiveness of alkali-activated grout with a common cement grout.

The soil used in the laboratory experiments was collected from the site where the field trials were later performed, sieved down to fractions below $1.18 \mathrm{~mm}$. The Class $\mathrm{F}$ (low calcium content) fly ash used was obtained from a thermo-electric plant. Its chemical composition is given in Table 1.

The chosen alkaline activator solution was a combination of sodium silicate solution and sodium hydroxide solution. The sodium silicate was in solution form, with a specific gravity of 1.5 and an $\mathrm{SiO}_{2} / \mathrm{Na}_{2} \mathrm{O}$ ratio of approximately $2: 1$ by mass. The sodium hydroxide was supplied in flake form, with a specific gravity of 2.13 at $20^{\circ} \mathrm{C}$ and $95-99 \%$ purity. The cement used to prepare laboratory samples was a Portland cement Type I, class $42.5 \mathrm{R}$. The mixer used was a $600 \mathrm{~W}$ kitchen appliance.

The activator/(soil + fly ash) ratio was kept constant during preparation of the samples, which meant that the activator/fly ash ratio was changed by variation of the fly ash percentage in the mixture. This ratio was of major significance for maintaining sufficient liquid phase to enable effective mixing, while preventing excessive liquidity. A ratio between 0.40 and 0.50 proved to be ideal. In order to determine the effect of the alkali-metal concentration, three different sodium hydroxide $(\mathrm{NaOH})$ concentrations were used: $10,12.5$ and 15 molal. Preparation of the samples with 15 molal hydroxide concentration was far less straightforward than with lower concentrations. This was because the $\mathrm{SiO}_{2} / \mathrm{Na}_{2} \mathrm{O}$ weight ratio for the 15 molal mixtures was approximately 1 , making the metasilicate solution very unstable, such that at higher temperatures it remains in solution form, but when cooled down it usually crystallises. This crystallisation occurred several times during preparation of the cold activator samples, and in most cases by the end of the mixing phase the mixture had become very viscous. Warming of the activator was found to prevent this problem occurring. Based on general alkaline activation research available in the literature (Hardjito and Rangan, 2005) and previous experience (Teixeira Pinto, 2006), it was decided to use a ratio of sodium silicate solution to sodium hydroxide solution, by mass, of 2 . This was fixed because the sodium silicate was considerably cheaper than the hydroxide, and no significant gains have ever been reported with smaller ratios.

When sodium hydroxide and sodium silicate solutions are mixed 


\begin{tabular}{lccccccccc}
\hline Component & $\mathrm{SiO}_{2}$ & $\mathrm{Al}_{2} \mathrm{O}_{3}$ & $\mathrm{Fe}_{2} \mathrm{O}_{3}$ & $\mathrm{CaO}$ & $\mathrm{MgO}$ & $\mathrm{K}_{2} \mathrm{O}$ & $\mathrm{TiO}_{2}$ & Others & LOI* \\
\hline Percentage & 52.74 & 23.62 & 8.9 & 5.56 & 2.12 & 1.13 & 1.25 & 4.68 & 2.59 \\
\hline
\end{tabular}

* LOI, loss on ignition.

Table 1. Chemical composition of the fly ash used

together, the chemical reactions developed are highly exothermic. Furthermore, according to Fernández-Jiménez et al. (2006), the $\mathrm{Si} / \mathrm{Al}$ ratio of aluminosilicate gel that is obtained from alkaline activation of fly ash F is highly dependent on, among other factors, the synthesis temperature. This is important because several authors (Duxson et al., 2005; Fletcher et al., 2005; Provis et al., 2005) highlight the importance of the $\mathrm{Si} / \mathrm{Al}$ ratio on the mechanical behaviour of any alkaline-activated material. However, the heat generated in the laboratory mixing $\left( \pm 30^{\circ} \mathrm{C}\right)$ was significantly lower than that expected for the larger quantities mixed in the field $\left(>50^{\circ} \mathrm{C}\right)$. This is why the warm activator, used in half of all the samples tested in this work, was kept in an oven at approximately $50^{\circ} \mathrm{C}$.

Three $76 \mathrm{~mm}$ long, $38 \mathrm{~mm}$ diameter samples were tested for unconfined compressive strength (UCS) per mixture. One complete set of samples made were wrapped in cling film and stored at ambient temperature and humidity conditions. The other set was buried in wet sand (approximately 20\% moisture content) at a depth of about $20 \mathrm{~cm}$. The cement grout samples were prepared with water/cement ratios of $0.5,0.75$ and 1.0 , with cement percentages of 20,30 and $40 \%$, in order to be able to directly compare the effect of cement content on strength.

\section{Laboratory results}

\subsection{Characterisation of the original soil}

Geotechnical characterisation and mineralogical tests were performed, in accordance with BS 1377 (1990) Parts 1, 2, 4 and 7 (BSI, 1990a, b, c, d) on the soil collected from the site and are summarised in Figure 1 and Table 2. The soil was a sandy clay of low plasticity. The undrained triaxial tests were performed on

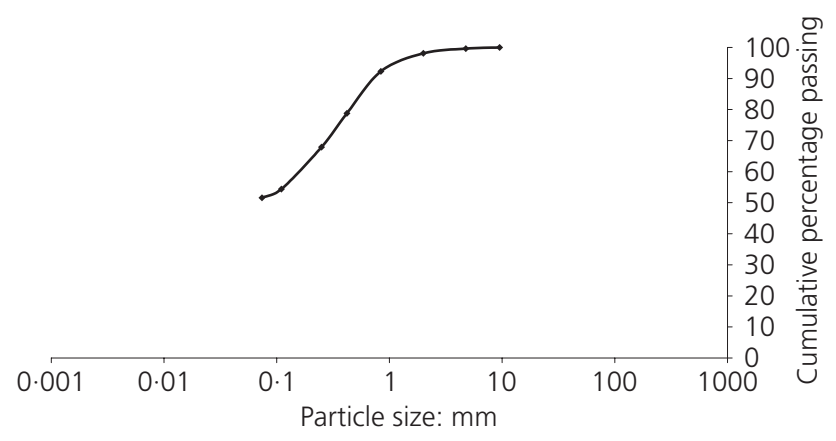

Figure 1. Particle size distribution saturated remoulded samples at the optimum water content. The XRD pattern showed the presence of quartz, kaolinite, muscovite (mica) and albite. All of these minerals are very common in this type of soil.

\subsection{Strength and stiffness of the stabilised soil}

Each of the compressive strength test data plotted corresponds to the mean value of the compressive strengths of three tests. Figure 2 shows the UCS results obtained with $40 \%$ fly ash, cold activator and normal and buried curing for the 10,12.5 and 15 molal hydroxide concentration. The addition of the grout increased the strength of the original dry soil progressively with curing time. The strength gain after 1 year curing is still increasing at the same rate as it was in the first 28 days. In both types of curing, and for all concentrations, there was no relevance of a peak value, which probably means that further strength developments can be expected with increased curing periods. The values for 12.5 and 15 molal were generally quite similar, suggesting that it is not effective, in terms of cost/improvement ratio, to use 15 molal concentrations. Although in the short term the 15 molal concentration mixture strength was higher than the 12.5 molal, the latter produced higher strength at 90 and 365 days, for both types of curing. That, together with the already-mentioned problems regarding the chemical stability of the 15 molal mixture, seems to indicate that the 12.5 molal mixtures are indeed the best option.

In terms of fly ash percentage, Figure 3 clearly indicates that the higher the fly ash content in the mixture the better the performance of the mixture in terms of strength development. This was verified in both curing conditions.

In addition to the 20, 30 and $40 \%$ fly ash mixtures a $50 \%$ mixture was also considered, with activator/fly ash ratios of 0.8 and 0.9 at 7 and 28 days curing. Figure 4 shows an increase in strength at 7 days curing for both activator/fly ash ratios and for both curing conditions. However, at 28 days curing (normal and buried curing) the 0.9 ratio resulted in a decrease in strength for the $50 \%$ fly ash mixture.

The decrease in activator/fly ash ratio was achieved without any increase in the amount of activator, which is a positive factor since the activator is comparably more expensive than fly ash. Further tests are necessary to confirm the idea that a reduction in activator/fly ash ratio achieved by just reducing the amount of activator could also lead to a strength increase. However, these 
PL

$\mathrm{LL}$

Optimum water content

Maximum dry density

Deviator stress at failure

Cell pressure

Strain at failure
$200 \mathrm{kPa}$

$9 \cdot 46 \%$

Table 2. Soil properties

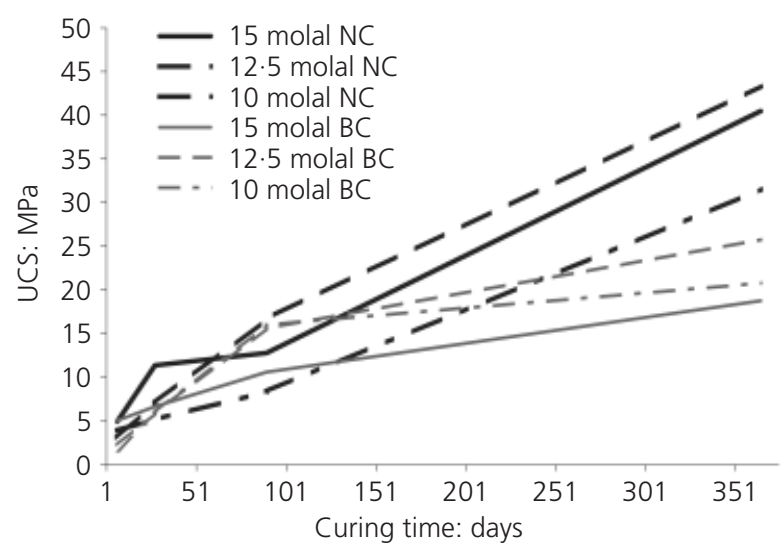

Figure 2. UCS for 10, 12.5 and 15 molal concentration mixtures with $40 \%$ fly ash and normal (NC) and buried (BC) curing

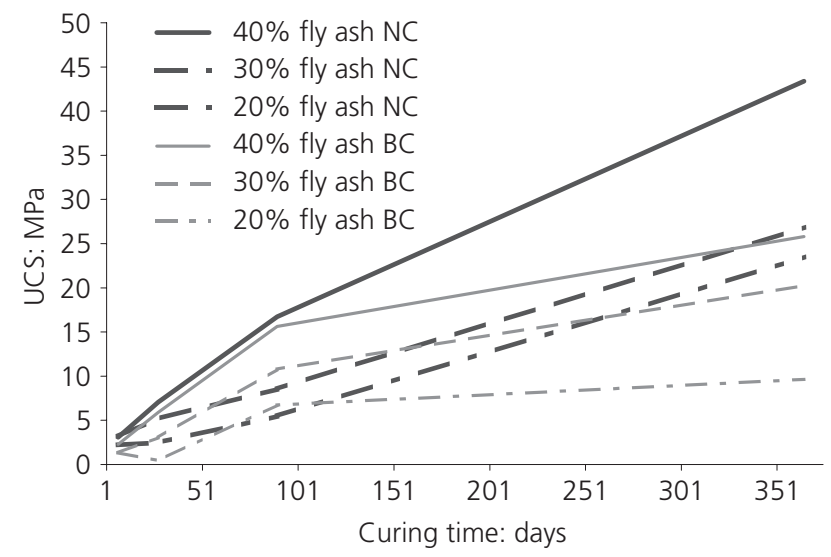

Figure 3. UCS for 20,30 and $40 \%$ fly ash content for 12.5 molal concentration mixtures and normal (NC) and buried (BC) curing

tests cannot be performed under the same conditions established during the research reported herein. This is because the only water added to the mixture was the water already present in the activator components, and preliminary tests showed that lower quantities of activator would not provide enough liquid to obtain a homogeneous mixture. Therefore the tests would have to be made in the field, first mixing the activator and the fly ash and only then injecting and mixing it with the soil.

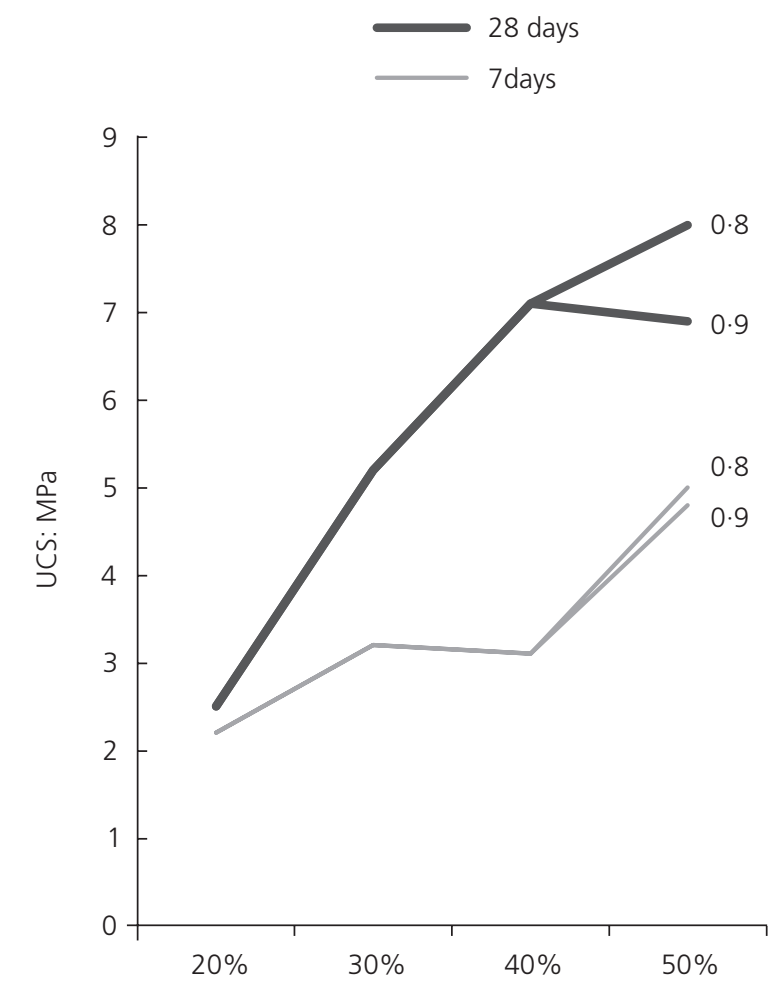

Figure 4. UCS comparison between 20, 30, 40 and 50\% fly ash mixtures (12.5 molal concentration - cold activator - normal curing -0.8 and 0.9 activator/fly ash ratios)

The UCS development rate was similar for the samples made with cold and warm activator, however there was a significant difference regarding absolute values, with cold activator mixtures reaching higher values especially at 90 days curing and beyond (Figure 5). When using a potassium-based activator to stabilise a class F fly ash, van Jaarsveld et al. (2002) reported that initial curing (no more than a couple of hours) at higher temperatures, which can be considered a situation similar to the warming of the activator immediately prior to the mixing, did not increase compressive strength substantially above that achieved with curing at room temperature. Only when the increase in temperature lasts longer do the positive effects on compressive strength become apparent. The same authors also concluded that curing for longer periods of time (more than $24 \mathrm{~h}$ ) at elevated temperature possibly weakened the structure and suggests that small 


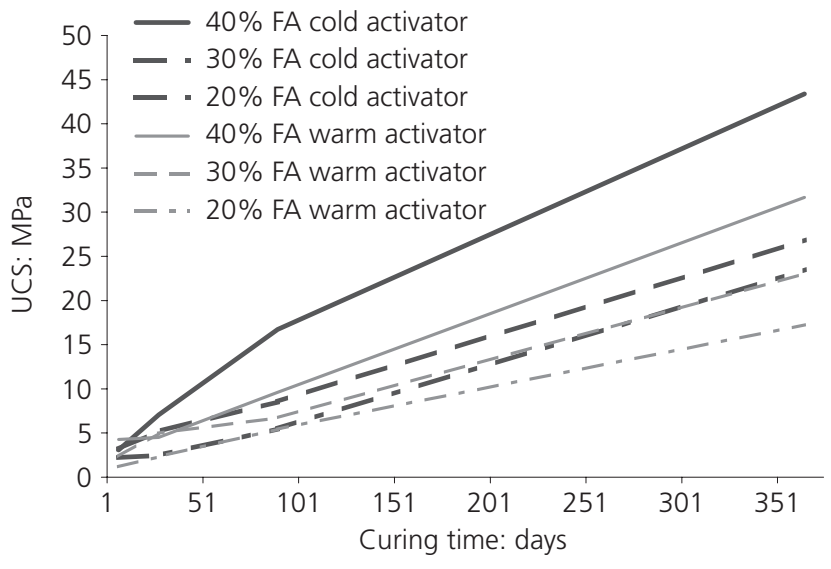

Figure 5. UCS comparison between 20, 30 and $40 \%$ fly ash mixtures prepared with cold and warm activator ( 12.5 molal concentration - normal curing)

amounts of structural water are needed in order to reduce cracking and maintain structural integrity.

It is also possible to conclude that, in general, burying the samples did not significantly reduce their strength performance, but only up to 90 days curing (Figure 3). The 20 and 30\% fly ash samples indeed revealed higher UCS, after 90 days, than the equivalent normal-cured samples. After that time though, normal curing had a significantly better influence on strength development, as these values were more than double the values registered for the buried curing at 365 days. This might be due to temperature differences, as the temperature of the wet sand where the samples were kept was colder (between 2 and $5^{\circ} \mathrm{C}$ ) than the ambient temperature.

\subsection{Comparison with a cement grout}

The curing period of all the cement samples tested was 28 days since it coincides with one of the curing periods used during the study of the alkaline-activated mixtures, and also because it is a reference curing period in soil stabilisation (cement and lime) and in the cement and concrete industry in general. The results obtained after such a period can be a good indicator of the final strength characteristics of the mixtures. The cement content was defined as the dry mass ratio between cement and soil.

A direct comparison between cement and alkaline grouts is shown in Figure 6. A water/cement (w/c) ratio of 1.0 was used as this is the most common w/c ratio in general practice. Comparison for curing periods longer than 28 days was necessary because it is well known that binders based on traditional Portland cement achieve most of their final strength after 28 days curing, whereas for the alkaline activator samples that period was revealed to be short for significant strength development.

A concrete-related mathematical expression to estimate the strength gain for the cement mixtures at 90 and 365 days curing

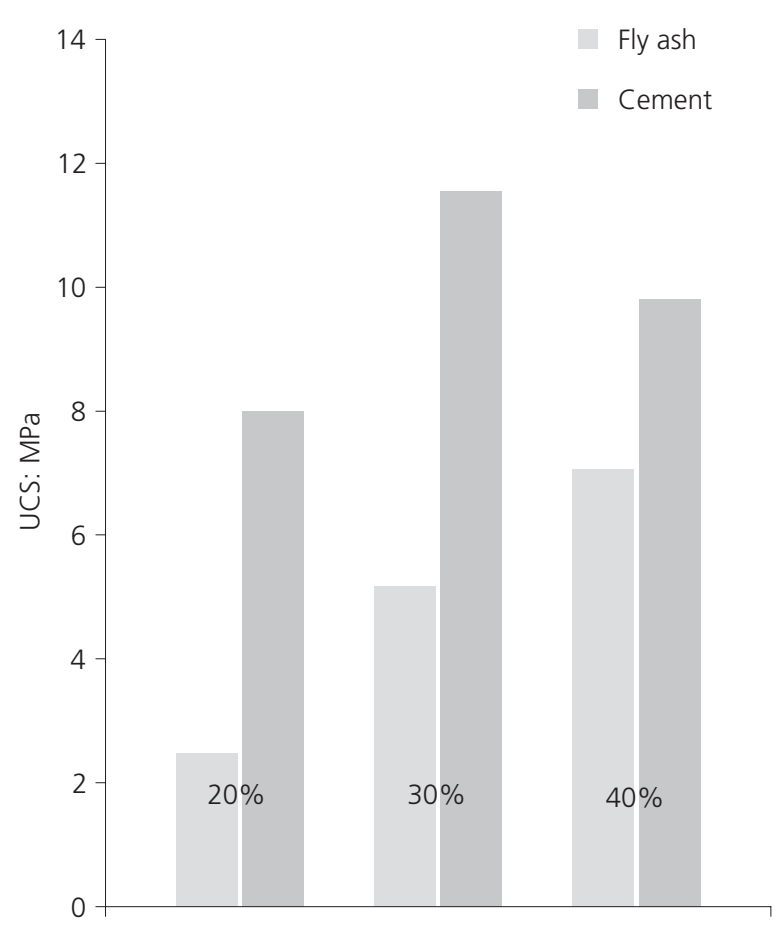

Figure 6. UCS comparison between cement $(\mathrm{w} / \mathrm{C}=1.0)$ and 12.5 molal (cold activator - normal curing) at 28 days curing

was used. This was mostly because an estimation that was specific for a typical soil-cement material could not be found, but also because in terms of chemical and mineralogical composition the two materials are not so different, which makes the concrete approach significantly similar. The compressive strength of concrete at an age $t$ depends on the type of cement, the temperature and the curing conditions. For a mean temperature of $20^{\circ} \mathrm{C}$, BS 1992-1-1:2004 (BSI, 2004) recommends the following relationship for moist-cured concrete made with normal Portland cement (class CEM $42.5 \mathrm{~N}$ ), where $f_{\mathrm{cm}}$ is the mean compressive strength at 28 days curing

\section{1. $f_{\mathrm{cm}}(t)=\beta_{\mathrm{cc}}(t) \cdot f_{\mathrm{cm}}$}

with

2. $\beta_{\mathrm{cc}}(t)=\exp \left\{s\left[1-\left(\frac{28}{t}\right)^{1 / 2}\right]\right\}$

where $f_{\mathrm{cm}}(t)$ is the mean compressive strength at an age $t$ (in days); and $s$ is a coefficient which depends on the type of cement $(0 \cdot 25$ for class CEM $42.5 \mathrm{~N})$.

This comparison is not meant to be considered precise or capable of generating final conclusions about the capabilities of the alkaline activator technique, but only as a mere reference for the 
strength gain rate and final values of this new binder. Since the buried curing can be considered most similar to a real field situation, and because cement grout samples achieved better results in that curing condition, the significantly superior results delivered by the alkaline activator normal cure mixtures should be acknowledged with some moderation, and so the buried curing results are considered more relevant for this study.

For the 12.5 molal concentration the results for 30 and $40 \%$ fly ash at 90 days were already at the same level as those estimated for the cement mixtures (Figure 7). At 365 days they were 33\% (30\% fly ash) and $73 \%$ ( $40 \%$ fly ash) higher than the estimated strength of the soil-cement material. Furthermore, the best cement result was reached at $30 \%$ content, which is not the highest content tested. This probably means this maximum strength cannot be raised by just increasing the cement content, whereas it was already established that by increasing the fly ash content on the alkaline activator grout above $40 \%$, further strength limits could be achieved. Even if at short term ( 28 days) the cement samples showed better behaviour in terms of strength development, and even considering the possibility that the strength gain estimation of the soil-cement mixtures is too conservative, there is a great probability that the medium- to long-term compressive strength of the soil-alkaline activator material is superior.

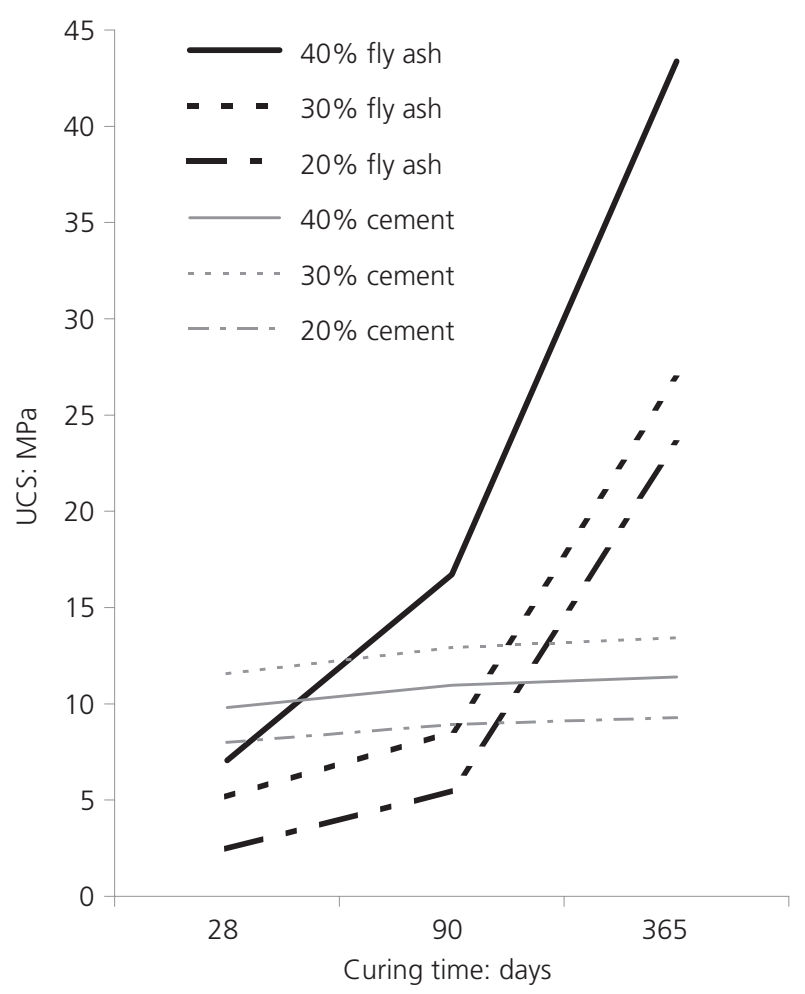

Figure 7. Comparison between 12.5 molal and cement $(w / c=1 \cdot 0)$ estimated strength (normal curing)
The following conclusions may be drawn from the laboratory tests.

(a) There was a strength gain with an increase in fly ash.

(b) Better results were obtained when a cold activator was used, which means that the activator should only be used when the heat generated from the exothermic reactions has dissipated to ambient temperature.

(c) An increase in activator concentration up to 15 molal was not beneficial, as the 12.5 molal concentration gave at least similar results, with the advantage of being cheaper and more chemically stable.

(d) Buried curing resulted in lower strength overall when compared with curing at ambient temperature and humidity; nevertheless there was a similar pattern in terms of strength evolution, with significant final values.

(e) The comparison with cement grouts showed that although at short term the alkaline-activated samples developed lower strength, at 3 months curing the strength was already higher than that of the cement samples.

\section{Field tests}

\subsection{Design and construction}

The field tests were performed using two different grouts corresponding to the 30 and $40 \%$ fly ash mixtures tested in the laboratory. The grout compositions are presented in Table 3.

The jet single system (BS EN 12716:2001) was chosen to produce the columns, as it is the cheapest and easiest system to use in practice (BSI, 2001). A set of cement grout columns was also constructed in order to evaluate the effect of each of the jet parameters on strength.

After careful analysis of the cement columns, and comparison

\begin{tabular}{lcc}
\hline Material & \multicolumn{2}{c}{ Percentage of total slurry } \\
\cline { 2 - 3 } & $30 \%$ fly ash & $40 \%$ fly ash \\
\hline Sodium hydroxide & $6 \cdot 7$ & 5.9 \\
Water & $13 \cdot 3$ & 11.8 \\
Sodium silicate & 40.0 & 35.2 \\
Fly ash & $40 \cdot 0$ & $47 \cdot 1$ \\
\hline
\end{tabular}

* This percentage refers to the grout + soil mixture.

$\dagger$ This percentage refers to the grout without the soil.

Table 3. Grout composition for 30 and $40 \%$ fly ash* 
with the respective jet parameters used, the parameters to build the alkaline columns were defined (Table 4).

\subsection{Field tests results}

In order to perform mechanical tests on the samples recovered from the column sections after 3 months curing, the excavation work began 11 weeks after the construction of the columns (Figure 8).

The strength of the first columns recovered was minimal, allowing breaking by hand, without much effort. By this time it was obvious that something had gone wrong regarding the formation of a column of soil with a strong alkaline matrix and a visual inspection of the columns revealed that little, if any, mixing between soil and grout had occurred (Figure 9).

Several hypotheses were formulated on why this segregation had happened, but after the laboratory work and the field tests with cement, it was obvious that it must be something to do with the jet parameters as some of the columns achieved good visual consistency levels (Figure 10), and the samples extracted from these achieved significant UCS values (Table 5).

It seems that the fact that these particular columns had a consistency and geometry that was closer to that expected had more to do with chance than with any specific subtleties of their grout composition or jet parameters. This idea is reinforced by the fact that between the columns that achieved satisfactory strength levels there were significant differences in the jet parameters used. Another factor contributing to this hypothesis is the similarity of jet parameters between these columns and some other columns that achieved very poor results.

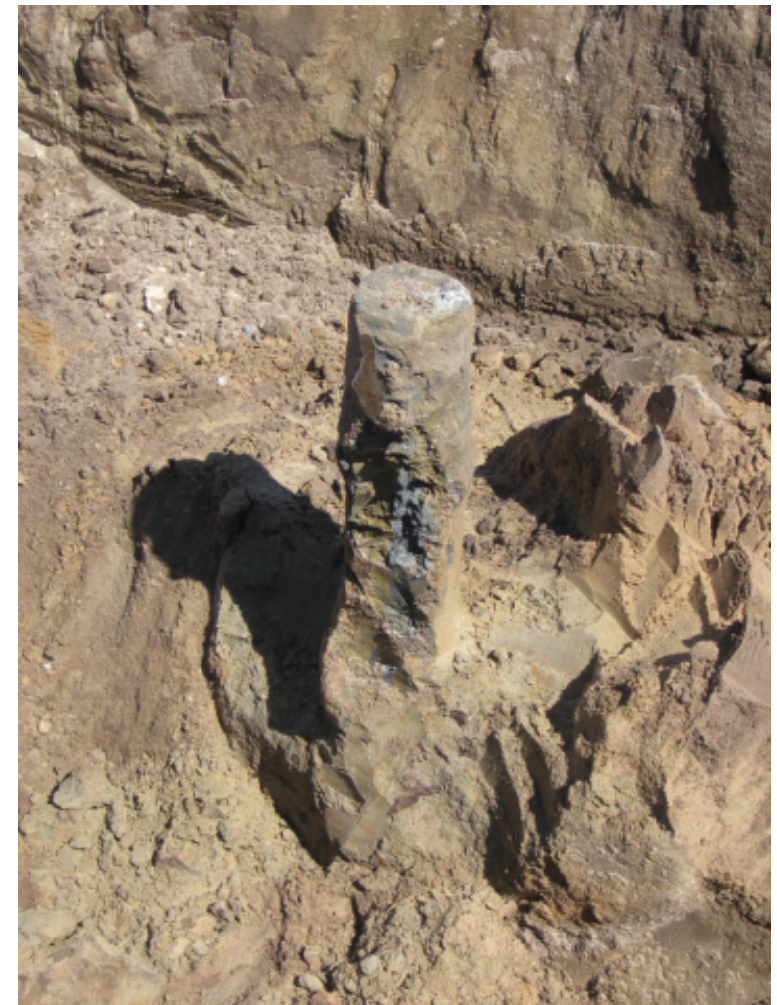

Figure 8. Excavation of the alkaline columns

It is important to emphasise that the UCS values are merely an indication of the possible results that might be achievable if the issues related to the jet parameters are resolved. Due to the insufficient number of samples recovered and consequently

\begin{tabular}{|c|c|c|c|c|c|c|c|c|}
\hline \multirow[t]{2}{*}{ Ref. } & \multirow{2}{*}{$\begin{array}{l}\text { Nozzle diameter } \\
\quad(\times 2): \mathrm{mm}\end{array}$} & \multirow{2}{*}{$\begin{array}{l}\text { Rotation speed: } \\
\text { rpm }\end{array}$} & \multicolumn{3}{|c|}{ Lift speed } & \multirow{2}{*}{$\begin{array}{c}\text { Flow rate: } \\
\text { l/min }\end{array}$} & \multirow{2}{*}{$\begin{array}{c}\text { Fluid pressure: } \\
\text { bar }\end{array}$} & \multirow{2}{*}{$\begin{array}{l}\text { Fly ash: } \\
\quad \%\end{array}$} \\
\hline & & & $\begin{array}{l}\text { Stage gap: } \\
\mathrm{cm}\end{array}$ & Time/stage: s & Ls: $\mathrm{m} / \mathrm{min}$ & & & \\
\hline$A$ & $1 \cdot 8$ & 67 & 6 & 8 & 0.40 & 45 & 80 & 30 \\
\hline B & & 67 & & 6 & 0.55 & & 80 & 30 \\
\hline C & & 26 & & 8 & 0.40 & & 100 & 30 \\
\hline D & & 26 & & 6 & 0.55 & & 100 & 30 \\
\hline$E$ & & 49 & & 8 & 0.40 & & 80 & 30 \\
\hline $\mathrm{F}$ & & 76 & & 8 & 0.40 & & 80 & 40 \\
\hline G & & 26 & & 8 & 0.40 & & 80 & 40 \\
\hline $\mathrm{H}$ & & 26 & & 8 & 0.40 & & 100 & 40 \\
\hline I & & 76 & & 8 & 0.40 & & 100 & 40 \\
\hline J & & 49 & & 8 & 0.40 & & 80 & 40 \\
\hline K & $1 \cdot 8$ & 49 & 6 & 2 & 1.60 & 45 & 40 & 40 \\
\hline $\mathrm{L}$ & & 49 & & 4 & 0.80 & & 20 & 40 \\
\hline M & & 76 & & 2 & 1.60 & & 40 & 40 \\
\hline $\mathrm{N}$ & & 76 & & 4 & 0.80 & & 20 & 40 \\
\hline
\end{tabular}

Table 4. Parameters used for the alkaline activator columns 


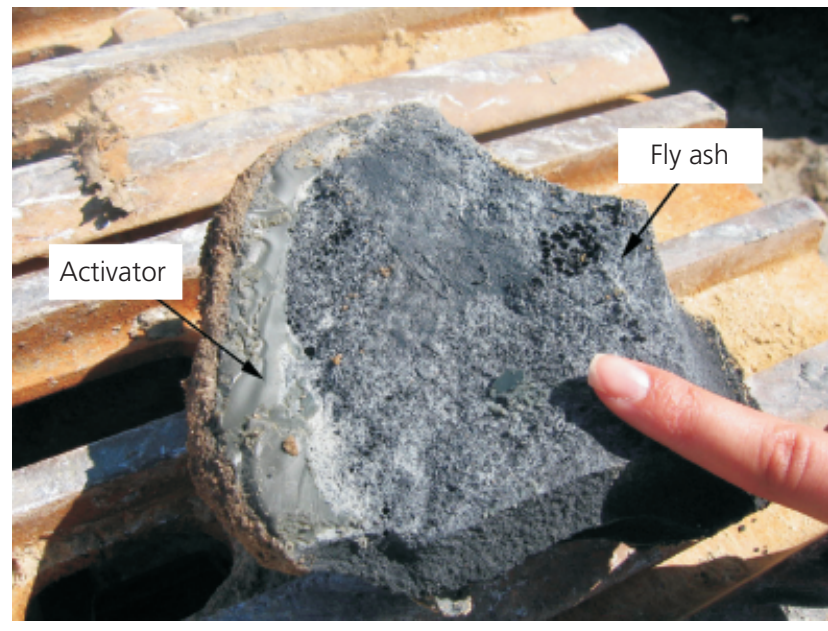

Figure 9. Segregation between grout components, with the activator in a very soft state

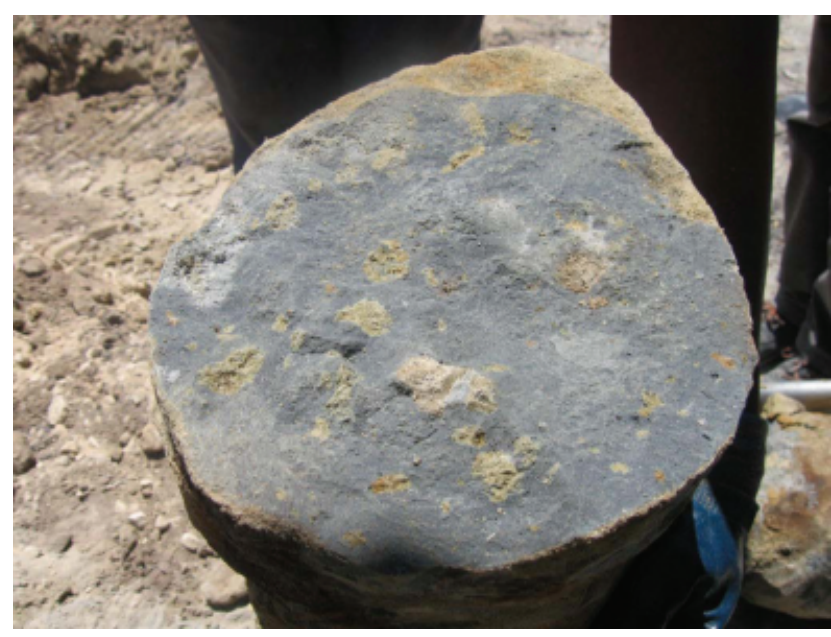

Figure 10. Section of column $\mathrm{G}$ with less material segregation

insufficient strength results obtained, they cannot be considered as statistically reliable. Furthermore, because of the reduced length of the sections that could be recovered, the direction of the samples for UCS tests, related to the column axis, was chosen with the intention of maximising the number of samples. This explains why most samples do not have a height/diameter ratio of 2 , which is the normal value for unconfined compression tests of stabilised soil samples (BSI, 1990a).

The comparison with the UCS results obtained from the cement grout samples from one of the columns is also relevant. The average strength for the cement column, $6.6 \mathrm{MPa}$, which was derived from values of $4.65,5.33$ and $9.8 \mathrm{MPa}$, was inferior to the average values obtained from column $\mathrm{C}(9 \cdot 1 \mathrm{MPa})$ and column G (15.3 MPa).

\begin{tabular}{|c|c|c|c|c|}
\hline \multirow[t]{2}{*}{$\begin{array}{l}\text { Column } \\
\text { reference }\end{array}$} & \multicolumn{2}{|c|}{$\begin{array}{l}\text { Recovered samples } \\
\text { dimensions: } \mathrm{cm}\end{array}$} & \multirow[t]{2}{*}{$\begin{array}{c}\text { Mass: } \\
\text { g }\end{array}$} & \multirow[t]{2}{*}{$\begin{array}{l}\text { UCS: } \\
\text { MPa }\end{array}$} \\
\hline & Diameter & Height & & \\
\hline \multirow[t]{3}{*}{ C } & $6 \cdot 9$ & $8 \cdot 3$ & $583 \cdot 3$ & 4.4 \\
\hline & $6 \cdot 9$ & 8.7 & $510 \cdot 8$ & $4 \cdot 6$ \\
\hline & $6 \cdot 9$ & $10 \cdot 2$ & 723.6 & $18 \cdot 3$ \\
\hline \multirow[t]{5}{*}{ G } & $6 \cdot 9$ & $5 \cdot 2$ & 332.8 & $9 \cdot 4$ \\
\hline & $6 \cdot 9$ & $6 \cdot 1$ & 401.8 & $13 \cdot 2$ \\
\hline & $6 \cdot 9$ & $11 \cdot 2$ & 672.9 & $12 \cdot 1$ \\
\hline & $6 \cdot 9$ & $12 \cdot 2$ & $899 \cdot 1$ & $26 \cdot 4$ \\
\hline & $6 \cdot 9$ & $13 \cdot 8$ & $891 \cdot 2$ & $6 \cdot 2$ \\
\hline \multirow[t]{3}{*}{ K } & $6 \cdot 9$ & $6 \cdot 0$ & $452 \cdot 5$ & $7 \cdot 2$ \\
\hline & $6 \cdot 9$ & $11 \cdot 2$ & $813 \cdot 7$ & $2 \cdot 6$ \\
\hline & $6 \cdot 9$ & $13 \cdot 4$ & 1031.9 & 3.6 \\
\hline
\end{tabular}

Table 5. Unconfined compressive strength of columns C, G and K

Figure 11 shows a comparison between the results from Table 5, the cement columns and the results from the laboratory tests which best fit the conditions used to build the columns during the field trials. These laboratory results were obtained for the following conditions

(a) curing period: 90 days

(b) sodium hydroxide concentration: 12.5 molal

(c) fly ash percentages: 30 and $40 \%$

(d) curing conditions: 'cold-normal curing' and 'cold-buried curing'.

For both fly ash percentages of $30 \%$ (column K) and $40 \%$ (columns $\mathrm{C}$ and $\mathrm{G}$ ) it is clear that, outlier points excluded, the

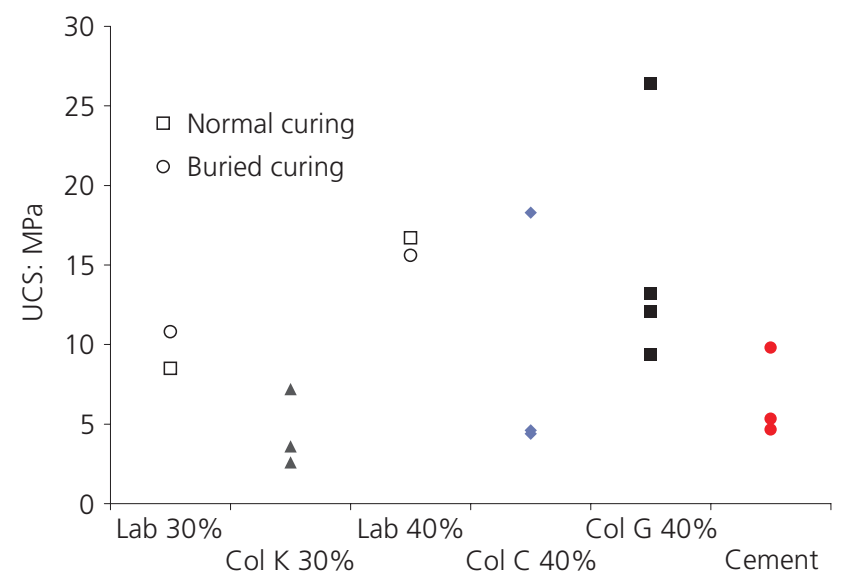

Figure 11. Comparison between UCS of samples from columns $C$, $\mathrm{G}$ and $\mathrm{K}$ and laboratory UCS results -90 days and 12.5 molal 
results obtained in the field were in accordance with those from the laboratory tests. The field/laboratory strength ratio was $1 \cdot 05$, 0.87 and 0.32 for columns $\mathrm{K}, \mathrm{G}$ and $\mathrm{C}$, respectively. Although there is not enough data for a statistical approach and analysis, these results give a good reference regarding the potential of the technique, if jet grouting-specific issues are addressed and solved.

\section{Conclusions}

Extensive laboratory testing led to the following conclusions.

(a) Fly ash class F activated with sodium produced a paste which when mixed with soil and hardened formed a new material with significantly improved mechanical strength and deformation. This improvement was time dependent, revealing a significant increase after 1 year of curing, in a process completely different from those using more common binders, such as Portland cement, which gain most of their strength at 28 days curing.

(b) The alkaline activation of this waste by-product is a simple process and it does not involve any sophisticated or costly procedures, or even any specialised or dangerous techniques.

(c) Use of the activator increased temperature - due to the exothermic reactions between its components - but reduced strength when compared with ambient temperature-activated samples.

(d) In comparison with cement results, alkaline grout mixtures showed higher strength. However, in the short term, cement had a faster strength gain rate.

The field trial concluded that regarding the preparation of the grout, there was not much difference between alkaline-activated grout and cement, meaning that there is no significant time delay involved in the fabrication of this new grout. Furthermore, in terms of strength results it is important to remember that contrary to cement, which reaches approximately 80 to $85 \%$ of its final strength after 28 days, alkaline-activated fly ash strength, after 3 months, was only at 40 to $60 \%$ of its 1 -year strength. However, UCS tests on samples obtained from sections recovered from alkaline and cement columns showed that at 3 months curing the strength level of the alkaline grout columns was greater than cement columns. Therefore, further research is needed to determine whether the difference in the strength gain rate is significant and, if that is the case, to develop ways to increase the speed of the reactions of the alkaline grout.

The main conclusion, based on the results obtained during this study, is that alkaline activation is a viable technique to be applied to soil stabilisation, more specifically to jet grouting columns, and is competitive with more traditional grouts, such as cement.

\section{REFERENCES}

BSI (British Standards Institution) (1990a) BS 1377: Part 1:

Methods of test for soils for civil engineering purposes: general requirements and sample preparation. BSI, Milton Keynes, UK.

BSI (1990b) BS 1377: Part 2: Methods of test for soils for civil engineering purposes - classification tests. BSI, Milton Keynes, UK.

BSI (1990c) BS 1377: Part 4: Methods of test for soils for civil engineering purposes - compaction-related tests. BSI, Milton Keynes, UK.

BSI (1990d) BS 1377: Part 7: Methods of Test for Soils for Civil Engineering Purposes - Shear Strength Tests. BSI, Milton Keynes, UK.

BSI (2001) BS EN 12716: Execution of special geotechnical works - jet grouting. BSI, Milton Keynes, UK.

BSI (2004) BS 1992: Part 1-1: Eurocode 2: Design of concrete structures - general rules and rules for buildings. BSI, Milton Keynes, UK.

Duxson P, Lukey GC, van Deventer JSJ, Mallicoat SW and Kriven WM (2005) Microstructural characterization of metakaolinbased geopolymers. Advances in Ceramic Matrix Composites X: Proceedings of the 106th Annual Meeting of the American Ceramic Society, Indianapolis, Ceramic Transactions, Vol 165 (Singh JP, Bansal NP and Kriven WM (eds.)). Wiley, Indianapolis. 71-85.

Feng D, Tan H and van Deventer J (2004) Ultrasound enhanced geopolymerisation. Journal of Materials Science 39(2): 571580 .

Fernández-Jiménez A, Palomo A, Sobrados I and Sanz J (2006) The role played by the reactive alumina content in the alkaline activation of fly ashes. Microporous and Mesoporous Materials 91(1-3) 111-119.

Fletcher RA, MacKenzie K, Nicholson CL and Shimada S (2005) The composition range of aluminosilicate geopolymers. Journal of the European Ceramic Society 25(9): 1471-1477.

Granizo M (1998) Activation Alcalina de Metacaolin: Desarrolllo de Nuevos Materials Cementantes. $\mathrm{PhD}$ thesis, University Autonoma de Madrid (in Spanish).

Hardjito D and Rangan B (2005) Development and Properties of Low-Calcium Fly Ash-Based Geopolymer Concrete. Curtin University of Technology, Australia, Research Report 1.

Hu M, Zhu X and Long F (2009) Alkali-activated fly ash-based geopolymers with zeolite or bentonite as additives. Cement and Concrete Composites 31(10): 762-768.

Hua X and Deventer J (2000) The geopolymerization of aluminosilicate minerals. International Journal of Mineral Processing 59(3): 247-266.

Hua X and Deventer J (2003) Effect of source materials on geopolymerization. Industrial and Engineering Chemistry Research 42(8): 1698-1706.

Pacheco-Torgal F, Castro-Gomes J and Jalali S (2007) Alkaliactivated binders: a review - Part 1. Historical background, terminology, reaction mechanisms and hydration products. Construction and Building Materials 22(7): 1305-1314.

Palomo A, Grutzeck M and Blanco M (1999) Alkali-activated fly 
ashes, a cement for the future. Cement and Concrete Research 29(8), 1323-1329.

Provis J, Duxson P, Lukey G and van Deventer J (2005) Statistical thermodynamic model for $\mathrm{Si} / \mathrm{Al}$ ordering in amorphous aluminosilicates. Chemistry of Materials 17(11): 2976-2986.

Teixeira Pinto A (2006) Introduction to Geopolymers. UTAD Press, Portugal (in Portuguese). van Jaarsveld J, van Deventer J and Lukey G (2002) The effect of composition and temperature on the properties of fly ash- and kaolinite-based geopolymers. Chemical Engineering Journal 89(1): $63-73$.

Wang H, Li H and Yan F (2005) Synthesis and mechanical properties of metakaolinite-based geopolymer. Colloids and Surfaces A 268(1-3): 1-6.

\section{WHAT DO YOU THINK?}

To discuss this paper, please email up to 500 words to the editor at journals@ice.org.uk. Your contribution will be forwarded to the author(s) for a reply and, if considered appropriate by the editorial panel, will be published as a discussion in a future issue of the journal.

Proceedings journals rely entirely on contributions sent in by civil engineering professionals, academics and students. Papers should be $2000-5000$ words long (briefing papers should be 1000-2000 words long), with adequate illustrations and references. You can submit your paper online via www.icevirtuallibrary.com/content/journals, where you will also find detailed author guidelines. 